\title{
Contact toxicity of three insecticides for use in tier I pesticide risk assessments with Megachile rotundata (Hymenoptera: Megachilidae)
}

\author{
Graham R Ansell $^{\text {Corresp., } 1}$, Andrew J Frewin ${ }^{1}$, Angela E Gradish ${ }^{1}$, Cynthia D Scott-Dupree ${ }^{1}$ \\ ${ }^{1}$ School of Environmental Sciences, University of Guelph, Guelph, Ontario, Canada \\ Corresponding Author: Graham R Ansell \\ Email address: gansell@uoguelph.ca
}

The current pesticide risk assessment paradigm may not adequately protect solitary bees as it focuses primarily on the honey bee (Apis mellifera). The alfalfa leafcutting bee (Megachile rotundata) is a potential surrogate species for use in pesticide risk assessment for solitary bees in North America. However, the toxicity of potential toxic reference standards to $M$. rotundata will need to be determined before pesticide risk assessment tests (tier I trials) can be implemented. Therefore, we assessed the acute topical toxicity and generated $L D_{50}$ values for three insecticides: dimethoate (62.08 ng a.i./bee), permethrin (50.01 ng a.i./bee), and imidacloprid (12.82 $\mathrm{ng}$ a.i/bee). The variation in the mass of individual bees had a significant but small effect on these toxicity estimates. Overall, the toxicity of these insecticides to $M$. rotundata were within the 10-fold safety factor currently used with $A$. mellifera toxicity estimates from tier I trials to estimate risk to other bee species. Therefore, tier I pesticide risk assessments with solitary bees may not be necessary, and efforts could be directed to developing more realistic, higher-tier pesticide risk assessment trials for solitary bees. 
1 Contact toxicity of three insecticides for use in tier I pesticide risk assessments

2 with Megachile rotundata (Hymenoptera: Megachilidae)

3

4 Graham R. Ansell ${ }^{1}$, Andrew J. Frewin ${ }^{1}$, Angela E. Gradish ${ }^{1}$, Cynthia Scott-Dupree ${ }^{1}$

5

$6{ }^{1}$ School of Environmental Sciences, University of Guelph, Guelph, Ontario, Canada, N1G 2W1

7

8 Corresponding Author:

9 Graham Ansell

10 School of Environmental Sciences, University of Guelph, Guelph, ON, Canada, N1G 2W1

11 Email address: gansell@uoguelph.ca 


\section{Abstract}

13 The current pesticide risk assessment paradigm may not adequately protect solitary bees as it 14 focuses primarily on the honey bee (Apis mellifera). The alfalfa leafcutting bee (Megachile 15 rotundata) is a potential surrogate species for use in pesticide risk assessment for solitary bees in 16 North America. However, the toxicity of potential toxic reference standards to M. rotundata will 17 need to be determined before pesticide risk assessment tests (tier I trials) can be implemented.

18 Therefore, we assessed the acute topical toxicity and generated $\mathrm{LD}_{50}$ values for three 19 insecticides: dimethoate (62.08 ng a.i./bee), permethrin (50.01 ng a.i./bee), and imidacloprid 20 (12.82 ng a.i/bee). The variation in the mass of individual bees had a significant but small effect 21 on these toxicity estimates. Overall, the toxicity of these insecticides to M. rotundata were within the 10-fold safety factor currently used with $A$. mellifera toxicity estimates from tier I trials to estimate risk to other bee species. Therefore, tier I pesticide risk assessments with solitary bees may not be necessary, and efforts could be directed to developing more realistic, higher-tier pesticide risk assessment trials for solitary bees. 


\section{Introduction}

Bees are important pollinators in natural and agro-ecosystems (Smagghe \& Calderone, 2012). Solitary bees, which comprise the majority of North American bee species (Michener, 2007), are equally or more effective than honey bees (Apis mellifera) at pollinating a variety of crops (Vaughn et al., 2014)) and uncultivated plants. Despite their importance, solitary bees are underrepresented in bee research (Vaughn et al., 2014; EFSA, 2013).

Solitary bee population declines (Goulson et al., 2015; Koh et al., 2015; Potts et al., 2015; Leach \& Drummond, 2018) have raised concerns about our ability to predict the potential effect of pesticides on them. Current pesticide risk assessment practices in North America and the European Union focus almost exclusively on A. mellifera (EFSA, 2013; EPA, 2014), and they do not account for the characteristic differences in life history, physiology, and behaviour between solitary bees and $A$. mellifera that may result in higher pesticide susceptibility or exposure for solitary bees (Sgolastra et al., 2018).

International efforts are underway to develop pesticide risk assessment protocols that will include solitary bees and more accurately assess their routes of exposure and susceptibility to pesticides (EFSA, 2013; EPA, 2014; Fischer \& Moriarty, 2014; OECD, 2017c; Sgolastra et al., 2018). As it is unfeasible to produce regulatory guidelines for every species of solitary bee, surrogate test species will need to be selected for different regions (Vaughn et al., 2014). The alfalfa leafcutting bee (Megachile rotundata Fabricius 1787) has been suggested as a potential surrogate for North American risk assessment for solitary bees, as its biology and behaviour are well understood, and individuals are commercially available in large quantities (Pitts-Singer \& Cane, 2011).

Regulatory pesticide risk assessment for bees is a three-tiered system involving tier I laboratory, tier II semi-field, and tier III field trials (OECD, 1998a, b; EPA, 2016). Tier I 
50

51

52

53

54

55

56

57

58

59

60

61

62

63

64

65

66

67

68

69

70

71

72

assessments are used as a screening tool to determine the acute toxicity of pesticides and filter out those that are unlikely to be toxic under proposed use conditions. If certain trigger values indicating potential harm are reached, products are moved to higher levels of testing. The exact protocols currently used are not appropriate for $M$. rotundata due to the behavioural and physical differences between $M$. rotundata and A. mellifera. For tier I pesticide risk assessments to be performed with $M$. rotundata, we must develop and use standardized methods that are unique to this species. These will be modified from existing risk assessment methods, but we must standardize the rearing methods, environmental conditions, treatment protocols, and expected toxicity of reference standards for $M$. rotundata. In this paper, we performed a series of toxicity tests to contribute towards the development of a standardized tier I test for M. rotundata based on those used by OECD (1998a) and similar to Piccolomini et al. (2018b).

The recent development of acute oral toxicity testing methods for Bombus spp. (OECD, 2017) is an excellent example of what can be done to develop M. rotundata topical toxicity tests. The Bombus protocols were based on the acute oral toxicity test for $A$. mellifera (OECD, 1998a) and modified for use with Bombus spp. in North America and the European Union (OECD, 2017). Similarly, A. mellifera toxicity testing methods (OECD 1998b) can be modified for $M$. rotundata, including modifications to rearing protocols, environmental requirements, and toxic reference standard values that are inherently different between the two species $(O E C D, 1998$; Vaughn et al., 2014; Piccolomini et al., 2018b). Using modified meathods from OECD (1998a) allows for robust comparisons of toxicity between species.

First, a reference standard with a known toxic effect is required for tier I pesticide risk assessments: The toxic reference standard is used in parallel with the pesticide under examination to confirm exposure of the test organism during the experiment $(E P A, 2012)$. We 
73 determined the acute contact toxicity of dimethoate, permethrin, and imidacloprid, potential toxic

74 reference standards for use in tier I trials, to adult female M. rotundata. Dimethoate is an

75

76

77

78

79

80

81

82 organophosphate insecticide currently used as a toxic reference standard in A. mellifera risk assessment and suggested as a toxic reference standard for pesticide risk assessment with Osmia spp. and Bombus spp. (OECD, 1998b; 2017b; Uhl et al., 2016). Permethrin is a commonly used pyrethroid insecticide that has high acute toxicity to M. rotundata (Helson, Barber \& Kingsbury, 1994; Piccolomini et al., 2018b), making it an excellent candidate as a toxic reference standard. Imidacloprid is a neonicotinoid insecticide with systemic activity commonly used as a seed treatment, soil drench, or foliar spray. EFSA, (2012) suggests that a systemic insecticide be used as one of several toxic reference standards, and current data suggest that imidacloprid is highly toxic to M. rotundata (Scott-Dupree, Conroy \& Harris, 2009).

Second, we assessed the influence of individual M. rotundata body mass on the dose received (dose/g bee) from a fixed exposure to pesticide (Klostermeyer, Stephen \& Rasmussen, 1973; Peterson \& Roitberg, 2006; Peterson, Roitberg \& Peterson, 2006). Given that the effective dose of a pesticide received by an individual is inversely proportional to its body mass, larger individuals can be expected to receive a smaller dose of pesticide and therefore generally will be less susceptible to pesticides than smaller individuals. Uhl et al., (2016) found body size to have a weak relationship with the insecticide susceptibility of several bee species to topically applied dimethoate. Devillers et al., (2003) also reported the susceptibility of $A$. mellifera and non-Apis bees to pesticides was inversely proportional to body size across species. Body mass can also be expected to influence the susceptibility to pesticides between different-sized individuals of the same species. Therefore, in pesticide risk assessment scenarios where all individuals in a treatment receive the same amount of active ingredient, a higher

Peer) reviewing PDF | (2020:08:51667:2:0:NEW 15 Dec 2020) 
96

97

variance in body mass within a population will result in a higher variance in the response to the treatment. Megachile rotundata displays a higher variation in body mass between adult individuals than A. mellifera (Helson, Barber \& Kingsbury, 1994), which may increase the variation of doses received within and between sample test populations. If this variation in individual mass is not measured and included in current pesticide risk assessment methods for bees, it is likely to decrease the precision and consistency of toxicity estimates for $M$. rotundata in tier I trials.

\section{Methods}

\section{Test insects}

Megachile rotundata pre-pupae were purchased from NorthStar Seed Ltd. (Manitoba,

Canada) in November the year before the bees were used, and stored at $8{ }^{\circ} \mathrm{C}$. Bees were not used beyond 10 months of purchase to ensure that the adults that emerged were healthy (Richards, Whitfield \& Schaalje, 1987). Pre-pupae were placed in plastic containers and stored in a temperature-controlled walk-in growth cabinet (Coldstream Products of Canada LTD., Winnipeg, Manitoba, Canada, model WIDF) at 27-30 ${ }^{\circ} \mathrm{C}, 60 \% \mathrm{RH}$, and 12:12 h light and dark until adult emergence (3-4 wk later). Large holes were cut in the lid of each container and covered on the inside with fine wire mesh to allow for ventilation and prevent the bees from escaping. The holes were covered externally with fine polyester No-see-um fabric netting (Skeeta, Florida, USA) to prevent parasitoid wasps from moving between containers. Containers were checked every other day for parasitoids, and all adult parasitoids and visibly parasitized leaf cells were removed. In the second year, containers were placed in bags made from breathable low tunnel greenhouse screen to further restrict parasitoid mobility. Upon emergence, female bees were stored in groups of 10 in treatment cups (Figure 1) and fed $20 \%$ sucrose solution in a growth cabinet at $25^{\circ} \mathrm{C}, 50 \% \mathrm{RH}$, and $12: 12 \mathrm{~h}$ light and dark for $3 \mathrm{~d}$ to acclimate to experimental 
120 conditions. Treatment cups were composed of two 500-mL clear plastic cups, a piece of dental

121 wick soaking in a reservoir of $20 \%$ sucrose solution as a food source, and a bent piece of

122 aluminum mesh to provide a surface for the bees to stand on.

123

124

125

126

127

128

129

130

131

132

133

134

135

136

137

138

139

140

141

142

143

\section{Insecticide treatments}

The methods used to generate $\mathrm{LD}_{50}$ estimates were adapted from current $A$. mellifera tier I risk assessment (OECD, 1998b). Technical grade (90-100\% purity) (MilliporeSigma, Ontario, Canada) insecticides were used in the experiments: dimethoate ( 5 doses were tested, between 10 and $150 \mathrm{ng}$ a.i./bee), permethrin (5 doses between 10 and $90 \mathrm{ng}$ a.i./bee), imidacloprid (5 doses between 0.5 and $40 \mathrm{ng}$ a.i./bee) (Table 1). Insecticides were diluted in acetone. Bees were anesthetized with $\mathrm{CO}_{2}$ from a compressed gas canister for $40 \mathrm{~s}$ in groups of 10 , and $1 \mu \mathrm{L}$ of the corresponding insecticide solution was applied to the dorsal thorax of each bee using a micropipette inside a fume hood. Control bees were treated with acetone only. The bees were treated in a randomized complete block design, where blocks were separated across days and each block contained 10 bees of each treatment for a single insecticide (Table 1). Treated bees were placed in new post-treatment containers with fresh $20 \%$ sucrose solution and returned to the growth cabinet. Post-treatment containers were arranged randomly on the growth cabinet shelf. Mortality was recorded daily, and the bees were considered dead if they did not respond to a gentle squeeze on the thorax with forceps. After $3 \mathrm{~d}$, all bees were placed in the freezer for at least $1 \mathrm{~d}$, rinsed with de-ionized water, desiccated thoroughly in a drying oven at $47^{\circ} \mathrm{C}$, and weighed.

\section{Statistical analyses}

All significance values were tested at $\alpha=0.05$. Data were analyzed using a generalized linear model in $\mathrm{R}$ with the glm function using a binomial distribution and probit transformation ( $R$ Core Team, 2017). Individual bee mass was used as an explanatory variable, and each bee 
144 was treated as an experimental unit, as all bees were maintained under virtually identical

145 conditions. The significance of each explanatory variable was tested with a Wald test (Agresti,

146 1990). Control mortality was corrected for using the Henderson-Tilton equation (Henderson \&

147 Tilton, 1955). The data were also analyzed without mass as an explanatory variable to assess the

148 magnitude of the effect of individual bee mass on toxicity estimates. Model fit was approximated

149 by calculating the pseudo $\mathrm{R}^{2}$ using Equation 1 (Alain et al., 2009).

150

151

$$
\text { pseudo } R^{2}=100 \times \frac{\text { Null deviance }- \text { residual deviance }}{\text { null deviance }}
$$

formulated product of each insecticide and the $\mathrm{LD}_{50}$ generated in this study $(E F S A, 2013)$. the pesticide and produces a more accurate assessment of risk than the more conservative hazard quotient. Unfortunately, there are not enough data on $M$. rotundata pesticide exposure to accurately generate risk quotients at this time (EPA, 2012).

$$
\text { Hazard Quotient }=\frac{\text { application rate }(g \text { a.i. } / h a)}{L D_{50}}
$$
without accounting for the mean mass of an A. mellifera adult worker and the mean mass of the M. rotundata females in this study. Further, a 10-fold safety factor was calculated from these $A$. mellifera values to address if the current tier I pesticide risk assessment methods are protective of M. rotundata when species body mass is accounted for. 


\section{Results}

Imidacloprid was more toxic than permethrin, which was slightly more toxic than dimethoate (Table 1). The slope of the dose response curve across all methods of bee mass incorporation was steepest for imidacloprid, followed by dimethoate, and then permethrin (Table 2, Figure 2). When the mean mass of individual adults of each species (M. rotundata and $A$. mellifera) was not taken into account, imidacloprid and dimethoate were more toxic to $M$. rotundata than $A$. mellifera (Table 3). However, all three insecticides were less toxic to $M$. rotundata than $A$. mellifera when the mean mass of individual adults was accounted for (Table mg.

All surviving bees treated with imidacloprid at all doses exhibited various degrees of rigid paralysis (Sharf, 2008) for the duration of the experiment, indicating that imidacloprid affects bees for more than $72 \mathrm{~h}$. It is thus unclear how many bees would fully recover, remain moribund, or die from imidacloprid exposure. Paralyzed bees were characterized as having their

resting bee, but nearly unable to move. Paralyzed bees were observed both ventral side down and ventral side up, and responded to foreceps stimulation with varying degrees of leg and antennal twitching. The degree of paralysis seemed to be dose-dependent, where bees that were treated with higher doses were less able to move than bees treated with lower doses. Bees treated with dimethoate exhibited varying degrees of jerky movements such as abdominal spasms, uncoordinated locomotion, and difficulty righting (Williamson et al., 2013) in the first day, and sublethal toxicity symptoms. 
$\mathrm{LD}_{50}$ values generated when incorporating and not incorporating individual mass within each

192

193

194

196

197

198

199

200

201

202

203

204

205

206

207

208

209

210

211

212

insecticide were not different, as in all cases the confidence values overlapped between estimates

(Table 2). Models that did not include mass had higher fit statistics than models that did include bee mass within each insecticide (Table 2).

The hazard quotient value for dimethoate surpassed the proposed trigger value for solitary bees $(E F S A, 2013)$, while the hazard quotients for permethrin and imidacloprid did not (Table 4).

\section{Discussion}

Thus far, our study is the only assessment of the toxicity of permethrin, dimethoate, or imidacloprid for the purposes of tier I M. rotundata pesticide risk assessment method development. Based on our results, imidacloprid is a poor choice as a toxic reference standard because the paralysis it induced for the duration of this experiment made it difficult to assess mortality. Additionally, imidacloprid will likely continue to have a negative effect on survival beyond the short duration of a tier I risk assessment (usually 48 or $72 \mathrm{~h}$ ) because none of the bees treated with imidacloprid fully recovered in that time frame. In contrast, the observable sublethal effects of dimethoate and permethrin ceased by the end of the experiment, indicating that all individuals had either died or recovered. The cessation of toxic effects within a short time is beneficial when designing short-term trials as the onset and conclusion of effects are clear and occur within the test period. Using dimethoate as a toxic reference standard for tier I $M$. rotundata risk assessment would maintain continuity with other bee pesticide risk assessment methods, all of which use dimethoate, (OECD, 1998b; 2015; Knäbe et al., 2017). However, ring testing will be required to implement any of these insecticides as toxic reference standards for $M$. rotundata pesticide risk assessment. 
Our results suggest that incorporating individual mass in a dose response model will not improve the precision of the $\mathrm{LD}_{50}$ or model fit for acute topical application of insecticides to $M$. rotundata. Similarly, Helson, Barber \& Kingsbury, (1994) found that incorporating the mass of individuals in their models did not change $\mathrm{LD}_{50}$ estimates when assessing the effect of acute topical applications of six pesticides on four bee species (M. rotundata, A. mellifera, Andrena erythronii, and Bombus terricola). Although we found that mass had a significant effect on our models, there was not a significant change in toxicity estimates, and model fit decreased when individual mass was incorporated. Therefore, we conclude that incorporating individual mass when calculating $\mathrm{LD}_{50}$ estimates for the purposes of pesticide risk assessment with $M$. rotundata is not necessary.

However, we still recommend reporting the mean body mass of test populations in solitary bee pesticide risk assessment. The mean body mass of $M$. rotundata is affected by latitude (Pankiw, Lieverse \& Siemens, 2012), production protocols (Pitts-Singer \& Cane, 2011), environmental conditions, and food quality and quantity (Klostermeyer, Stephen \& Rasmussen, 1973; Rothschild, 1979). As risk assessments are based on data compiled from multiple experiments using sample populations from different locations, it would be prudent to report the mean body mass of the bees in these various experimental groups to account for some of the differences in estimates generated from different sample populations from different locations. This may help contextualize results across studies, and is a relatively simple endpoint to measure.

235 trigger values for solitary bees $\left(8-16 \frac{\mathrm{g} \text { a.i./ha }}{\mu \mathrm{g} \text { a.i./bee }}\right)$ proposed by $E F S A$, (2013). The trigger values 236 proposed by EFSA do not account for exposure and are more conservative than the risk quotient 
237 trigger values usually used in North America (EPA, 2012). However, without the M. rotundata

238 life history data required to generate a risk quotient, the hazard quotient generated here is the 239 most accurate estimate of potential risk to $M$. rotundata. Therefore, our data support that the

240 current safety factors used in North America to protect solitary bees in the field should be re241 examined.

242 Our results were similar to those found in other recent topical toxicity studies with $M$.

243 rotundata, although the variation in methods between those studies and ours prevent direct

244 comparison. Our $72 \mathrm{~h} \mathrm{LD}_{50}$ for permethrin (53.49 $\mathrm{ng}$ a.i./bee) was similar to the $24 \mathrm{~h} \mathrm{LD} 50$ of 57

245 ng a.i./bee reported by Piccolomini et al. (2018b). It was also similar to the $48 \mathrm{~h} \mathrm{LD}_{50}$ of $18 \mathrm{ng}$

246 a.i./bee reported by Helson, Barber \& Kingsbury (1994), although they kept their bees in post-

247 treatment containers at $16{ }^{\circ} \mathrm{C}$ which is almost $10{ }^{\circ} \mathrm{C}$ cooler than other experiments. Our $72 \mathrm{hr}$

$248 \mathrm{LD}_{50}$ for imidacloprid (17.36 ng a.i./bee) was within two-fold of the $48 \mathrm{~h} \mathrm{LD}_{50}$ generated by

249 Hayward et al. (2019) of $10 \mathrm{ng} / \mathrm{bee}$.

250 Our results suggest that while safety factors for solitary bees may need to be re-

251 examined, tier I solitary bee pesticide risk assessment may not be necessary within the current

252 framework. The toxicity of all 3 insecticides in our study were within the 10 -fold assessment

253 factor (1/10 the $\mathrm{LD}_{50}$ for $A$. mellifera) proposed by EFSA when compared to $A$. mellifera toxicity

254 estimates from the literature. This is consistent with the current literature where in nearly all

255 cases solitary bees are protected by the assessment factor: Arena \& Sgolastra, (2014) reported

256 that $95 \%$ of bee species studied in 44 laboratory trials were protected within the 10 -fold

257 assessment factor for 6 pesticides, Helson, Barber \& Kingsbury, (1994) found that 3 bee species,

258 including M. rotundata, were protected, and Uhl et al., (2016) found the 10-fold assessment

259 factor protective for 5 European bee species exposed to dimethoate. Piccolomini et al. (2018b) 
260 also reported similar $\mathrm{LD}_{50}$ values for 3 pyrethroids (including permethrin) for $M$. rotundata and

261 A. mellifera, and it was further demonstrated that the pyrethroid etofenprox was also not acutely

262 toxic to M. rotundata in field trials with commercial M. rotundata nesting units (Piccolomini et

263 al., 2018a). Furthermore, in our study M. rotundata was less susceptible than A. mellifera to all

264 three of the insecticides when body mass was accounted for, similar to the results reported by

265 Helson, Barber \& Kingsbury, (1994).

266 Hayward et al. (2019) also found that M. rotundata was within the 10-fold assessment

267 factor for imidacloprid, but was 2,500 fold more sensitive to thiacloprid and 170 fold more

268 sensitive to flupyradifurone than A. mellifera. The extreme sensitivity exhibited by $M$. rotundata

269 to thiacloprid and flupyradifurone is due to a lack of P450 enzymes in the CYP9Q subfamily that

270 are present other managed bees (Hayward et al., 2019). Therefore, it appears that in nearly all

271 cases the threshold values that are protective to A. mellifera via topical exposure in a laboratory

272 environment are likely to be protective of $M$. rotundata based on the 10-fold assessment factor.

273 Instead of developing costly protocols to address the few cases where the assessment factor is

274 not protective, alternative approaches may be more effective. Perhaps an additional assessment

275 factor may be developed for species lacking certain P450 enzymes, or insecticides that are

276 detoxified by those enzymes could be passed on to higher-tier tests automatically. Tier I tests

277 may even be developed for these fringe cases alone. We will not know the best course of action

278 until we understand more about solitary bees' responses to insecticides.

279 Despite the protectiveness of the 10-fold assessment factor in tier I trials, $A$. mellifera is

280 still unlikely to be a suitable surrogate for all bee species at the tier II and III scale. Laboratory

281 exposure experiments do not reflect many of the key differences in life history, behavior, and

282 sociality between M. rotundata and A. mellifera (EFSA, 2013; Sgolastra et al., 2018). For 
283 example, under more realistic conditions, solitary bee larvae may experience higher pesticide 284 exposure than $A$. mellifera larvae via contact with residues on leaf cuttings or soil used to 285 construct their cells, and as adults with smaller foraging ranges when in close proximity to 286 agriculture (Vaughn et al., 2014). Additionally, the death of a single female solitary bee has a 287 larger impact on the population's reproductive potential than the death of a single $A$. mellifera 288 worker. These behavioural and life history differences are more likely to result in differences in 289 susceptibility and exposure of solitary bees and $A$. mellifera at higher tiers of risk assessment that 290 cannot be extrapolated from tier I results. 


\section{Conclusion}

293 Our data suggest that dimethoate or permethrin may be suitable as a toxic reference standard for 294 tier I pesticide risk assessment for M. rotundata. However, thorough replication and method 295 development will be required before either insecticide can be incorporated into the risk 296 assessment process. Although we did not find that individual bee mass influences $\mathrm{LD}_{50}$ estimates 297 for $M$. rotundata, we recommend reporting the mean mass of sample populations as they may 298 vary between experiments and could affect toxicity estimates between studies. Finally, our 299 results suggest that it may not be necessary to develop topical tier I pesticide risk assessment 300 using $M$. rotundata, as the $\mathrm{LD}_{50}$ values that we generated were within a $10-$ fold assessment 301 factor of previously generated A. mellifera $\mathrm{LD}_{50}$ values as suggested by EFSA, (2013). 
302

303

304

305

306

307

308

309

310

311

312

313

314

315

316

317

318

319

320

321

322

323

324

325

326

327

328

329

330

331

332

333

334

335

336

337

338

339

340

341

342

343

344

345

346

347

\section{References}

Agresti A. 1990. Categorical data analysis, 3 ed. John Wiley \& Sons, Inc., New York, NY.

Alain FZ, Ieno EN, Walker NJ, Anatoly NA, Smith GM. 2009. Mixed effects models and extensions in ecology with R. Springer Science + Buisness Media, New York, NY. DOI: 10.1007/978-0-387-87458-6.

Arena M, Sgolastra F. 2014. A meta-analysis comparing the sensitivity of bees to pesticides. Ecotoxicology 23: 324-334. DOI 10.1007/s10646-014-1190-1.

Devillers J, Decourtye A, Budzinski H, Pham-Delègue MH, Cluzeau S, Maurin G. 2003. Comparative toxicity and hazards of pesticides to Apis and non-Apis bees. A chemometrical study. SAR and QSAR in Environmental Research 14: 389-403. DOI: 10.1080/10629360310001623980.

European Food Safety Authority (EFSA). 2012. Scientific opinion on the science behind the development of a risk assessment of plant protection products on bees (Apis mellifera, Bombus spp., and solitary bees). EFSA Journal 10: 275. DOI: 10.2903/j .efsa.2012.2668.

European Food Safety Authority (EFSA). 2013. Guidance on the risk assessment of plant protection products on bees (Apis mellifera, Bombus spp. and solitary bees). EFSA Journal 11: 268. DOI: 10.2903/j.efsa.2013.3295.

Environmental Protection Agency (EPA). 2012. White paper in support of the proposed risk assessment process for bees. Office of Chemical Safety and Pollution Prevention, Office of Pesticide Programs, Environmental Assessment Division, Washington, D.C.

Environmental Protection Agency (EPA). 2014. Guidance for assessing pesticide risk to bees. Office of Pesticide Programs, United States Environmental Protection Agency, Washington, D.C.

Environmental Protection Agency (EPA). 2016. Guidance on exposure and effects testing for assessing risks to bees. Office of Pesticide Programs, U.S. Environmental Protection Agency. Washington, D.C.

Fischer D, Moriarty T. 2014. Pesticide risk assessment for pollinators, First ed. Society of Environmental Toxicology and Chemistry (SETAC). John Wiley \& Sons, Inc., Oxford, United Kingdom.

Goulson D, Nicholls E, Botias C, Rotheray L. 2015. Bee declines driven by combined stress from parasites, pesticides, and lack of flowers. Science 347: 1255957-1255957. 10.1126/science. 1255957.

Hayward , Beadle K, Saurabh Sing K, Exeler N, Zaworra M, Almanza MT, Nikolakis A, Garside C, Glaubitz J, Bass C, Nauen R. 2019. The leafcutter bee, Megachile rotundata, is more sensitive to $N$-cyanoamidine neonicotinoid and butenolide insecticides than other managed bees. Nature Ecology \& evolution 3: 1521-1524. DOI: 10.1038/s41559-019-1011-2

Henderson CF, Tilton EW. 1955. Tests with acaricides against the brown wheat mite. Journal of Economic Entomology 48: 157-161. DOI: 10.1093/jee/48.2.157.

Klostermeyer EC, Stephen JM, Rasmussen WB. 1973. Sex and weight of Megachile rotundata (Hymenoptera: Megachilidae) progeny associated with provision weights. Journal of the Kansas Entomological Society 46: 536-548. www.jstor.org/stable/25082604.

Knäbe S, Franke L, Fricke J, Klein O, Alscher A, Classen C, Exeler N, Frommberger M, Guerola JS, Kimmel S, Lückmann J, Molitor C, Peters B, Hecht-Rost S, Shneider C. 2017. Summary of an ICPPR non-Apis workshop-subgroup higher TIER (bumble bees

Peer) reviewing PDF | (2020:08:51667:2:0:NEW 15 Dec 2020) 
and solitary bees) with recommendations for an semifield experimental design. DOI: 10.13140/RG.2.2.30425.72805.

Koh I, Lonsdorf EV, Williams NM, Brittain C, Isaacs R, Gibbs J, Ricketts TH. 2015. Modeling the status, trends, and impacts of wild bee abundance in the United States. PNAS 113: 140-145. DOI 10.1073/pnas.1517685113.

Leach ME, Drummond F. 2018. A review of native wild bee nutritional health. International Journal of Ecology 2018: 1-10. DOI: 10.1155/2018/9607246.

Organisation for Economic Co-operation and Development (OECD). 1998a. OECD guidelines for the testing of chemicals, Test No. 213: Honeybees, acute oral toxicity test. In OECD guidelines for the testing of chemicals section 2: effects on biotic systems. OECD Publishing, Paris, France. DOI: 10.1787/9789264070165-en.

Organisation for Economic Co-operation and Development (OECD). 1998b. OECD guidelines for the testing of chemicals, Test No. 214: Honeybees, acute contact toxicity test. In OECD guidelines for the testing of chemicals section 2: effects on biotic systems. OECD Publishing, Paris, France. DOI: 10.1787/9789264070189-en.

Organisation for Economic Co-operation and Development (OECD). 2017. OECD guidelines for the testing of chemicals, Test No. 247: bumblebee, acute oral toxicity test. In OECD series on testing and assessment. OECD Publishing, Paris, France. DOI 10.1787/9789264284128-en.

Pankiw P, Lieverse JAC, Siemens B. 2012. The relationship between latitude and the emergence of alfalfa leafcutter bees, Megachile rotundata (Hymenoptera: Megachilidae). The Canadian Entomologist 112: 555-558. DOI: 10.4039/Ent112555-6.

Peterson JH, Roitberg BD. 2006. Impact of resource levels on sex ratio and resource allocation in the solitary bee, Megachile rotundata. Environmental Entomology 35: 1404-1410. DOI: $10.1093 / \mathrm{ee} / 35.5 .1404$.

Peterson JH, Roitberg BD, Peterson JH. 2006. Impacts of flight distance on sex ratio and resource allocation to offspring in the leafcutter bee, Megachile rotundata. Behavioural Ecology and Sociobiology 59: 589-596. DOI: 10.1007/s00265-005-0085-9.

Piccolomini AM, Flenniken ML, O'Neill KM, Peterson RKD. 2018. The effects of an ultralow-volume application of etofenprox for mosquito management on Megachile rotundata (Hymenoptera: Megachilidae) larvae and adults in an agricultural setting. Journal of Economic Entomology 111: 33-38. DOI: 0.1093/jee/tox343.

Piccolomini AM, Whiten SR, Flenniken ML, O'Neill KM, Peterson, RKD. 2018. Acute toxicity of permethrin, deltamethrin, and etofenprox to the alfalfa leafcutting bee. Journal of Economic Entomology 111(3): 1001-1005. DOI: 0.1093/jee/toy014.

Pitts-Singer TL, Cane JH. 2011. The alfalfa leafcutting bee, Megachile rotundata: the world's most intensively managed solitary bee. Annual Review of Entomology 56: 221-237. DOI: 10.1146/annurev-ento-120709-144836.

Potts S, Biesmeijer K, Bommarco R, Breeze T, Carvalheiro L, Franzén M, González-Varo J, Holzschuh A, Kleijn A, Kunin B, Lecoq T, Lundin O, Michez D, Neumann P, Nieto A, Penev L, Rasmont P, Ratamäki O, Riedinger V, Robert S, Rundlöf M, Scheper J, Sørensen P, Steffan-Dewenter I, Stoev P, Vilà M, Schweiger O. 2015. Status and trends of European pollinators: Key findings from the STEP project. Pensoft Publishers, Sofia, Bulgaria.

R Core Team. 2017. R: A language and environment for statistical computing. R Foundation for Statistical Computing, Vienna, Austria. 
Rothschild M. 1979. Factors influencing size and sex ratios in Megachile rotundata (Hymenoptera: Megachilidae). Journal of the Kansas Entomological Society 52: 392401.

Sanchez-Bayo F, Goka K. 2014. Pesticide residues and bees - a risk assessment. PLOS ONE 9: 1-16. DOI: 10.1371/journal.pone.0094482.

Scott-Dupree CD, Conroy L, Harris CR. 2009. Impact of currently used or potentially useful insecticides for canola agroecosystems on Bombus impatiens (Hymenoptera: Apidae), Megachile rotundata (Hymenoptera: Megachilidae), and Osmia lignaria (Hymenoptera: Megachilidae). Journal of Economic Entomology 102: 177-182. DOI: 10.1603/029.102.0125.

Sgolastra F, Hinarejos S, Pitts-Singer TL, Boyle NK, Joseph T, Lūckmann J, Raine NE, Singh R, Williams NM, Bosch J. 2018. Pesticide exposure assessment paradigm for solitary bees. Environmental Entomology 20: 1-14 DOI 10.1093/ee/nvy105.

Sharf ME. 2008. Neurological effects of insecticides and the insect nervous system. In J. L. Capinera [ed.], Encyclopedia of entomology. Springer, Dordrecht, Netherlands.

Torchio PF. 1973. Relative toxicity of insecticides to the honey bee, alkali bee and alfalfa leafcutting bee (Hymenoptera: Apidae, Halictidae, Megachilidae). Journal of the Kansas Entomological Society 46: 446-453.

Uhl P, Franke LA, Rehberg C, Wollmann C, Stahlschmidt P, Jeker L, Brühl CA. 2016. Interspecific sensitivity of bees towards dimethoate and implications for environmental risk assessment. Scientific Reports-UK 6. DOI: 10.1038/srep34439.

Vaughn M, Vassière BE, Maynard G, Kasina M, Nocelli RCF, Scott-Dupree C, Johansen E, Brittain C, Coulson M, Dinter A. 2014. Chapter 3: overview of non-Apis bees, pp. 15-18 In D. Fischer and T. Moriarty (eds.), Pesticide risk assessment for pollinators. John Wiley \& Sons, Inc., Oxford, United Kingdom. DOI: 10.1002/9781118852408.ch3.

Whiten SR, Peterson RKD. 2016. The influence of ambient temperature on the susceptibility of Aedes aegypti (Diptera: Culicidae) to the pyrethroid insecticide permethrin. Journal of Medical Entomology 53: 139-143. DOI: 10.1093/jme/tjv159.

Williamson SM, Moffat C, Gomersall MAE, Saranzewa N, Connolly CN, Wright GA. Exposure to acetylcholinestrase inhibitors alters the physiology and motor function of honeybees. Frontiers in Physiology 4: 13. DOI: 10.3389/fphys.2013.00013. 
Figure 1

Post-treatment container design for topical $\mathrm{LD}_{50}$ experiments using Megachile rotundata.

(A) screened lid, B) outer 500-mL clear cup containing sugar solution. (C) inner 500-mL clear cup with hole in center for dental wick. (D) sugar solution. (E) aluminum mesh. (F) dental wick feeder soaking in sugar solution.

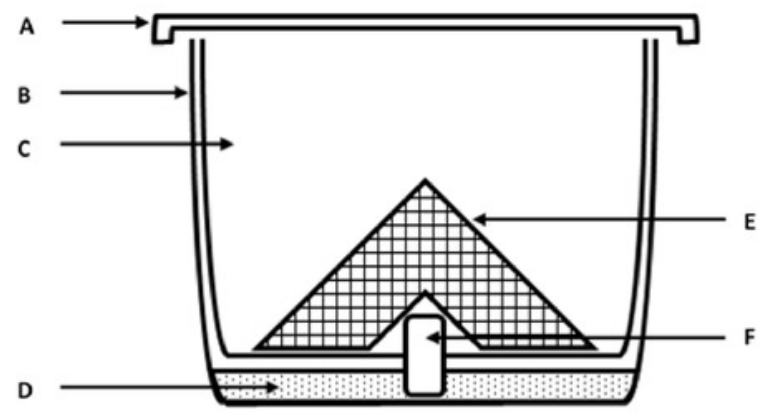


Figure 2

Dose response curves for mortality $72 \mathrm{~h}$ after topical exposure of female Megachile rodundata to dimethoate, permethrin, or imidacloprid.

These models did not include the body mass of individual bees as a covariate. $\mathrm{LD}_{50}$ values (ng a.i./bee) and $95 \%$ confidence intervals are represented by vertical black lines and gray rectangles, respectively. The standard error of predicted values is represented by the gray ribbon around the dose response curve. 


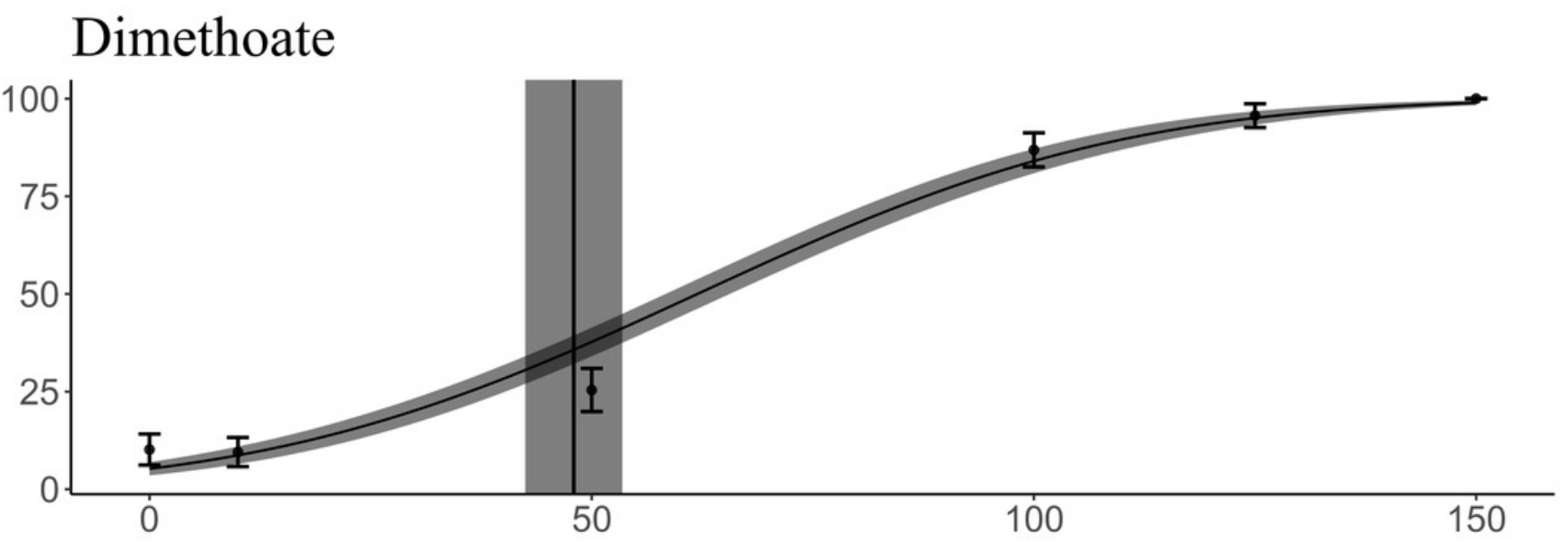

\section{Permethrin}

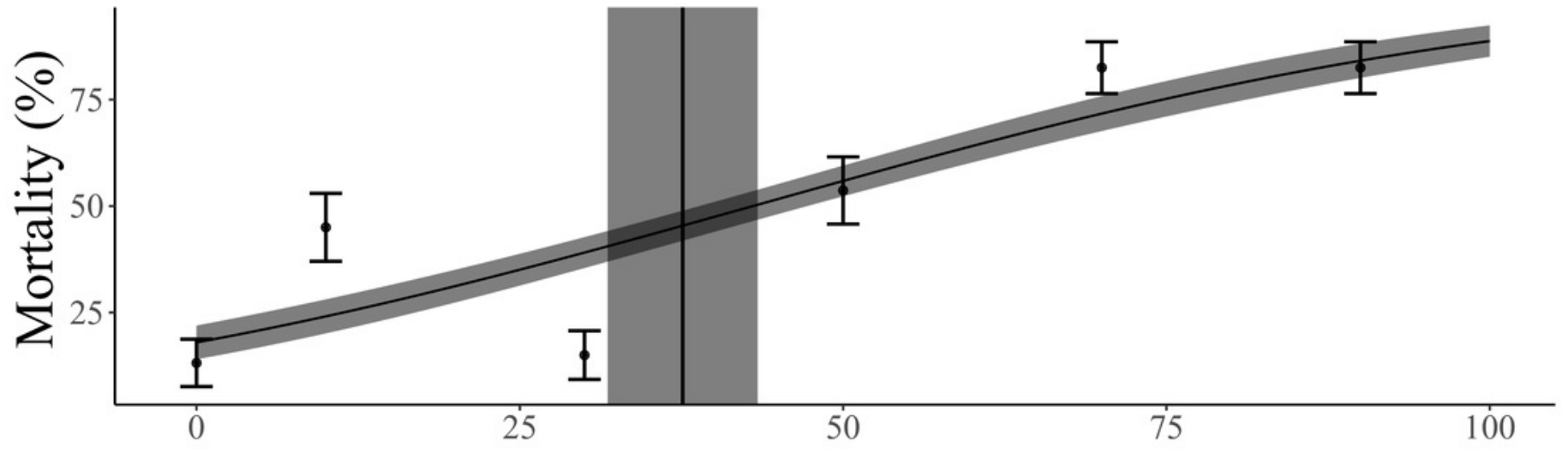

\section{Imidacloprid}

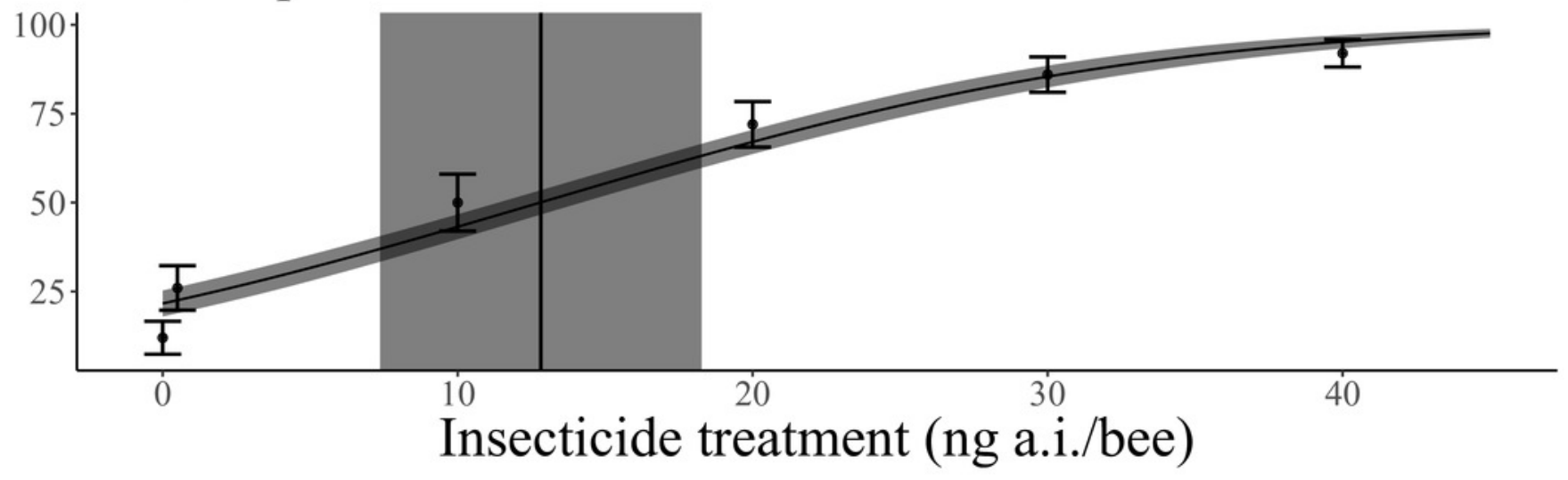




\section{Table $\mathbf{1}$ (on next page)}

Treatments, sample sizes, arithmetic mean mortality, and mean dry mass with standard deviation (SD) of female Megachile rotundata $72 \mathrm{hr}$ after topical exposure to three insecticides. 


\begin{tabular}{|c|c|c|c|c|}
\hline Insecticide & $\begin{array}{l}\text { Treatments } \\
\text { (ng a.i./bee) }\end{array}$ & Sample size & Mean mortality (\%) & $\begin{array}{c}\text { Mean dry mass } \\
\text { (SD) in mg }\end{array}$ \\
\hline \multirow[t]{6}{*}{ dimethoate } & 0 & 59 & 10.1 & $15.2(2.42)$ \\
\hline & 10 & 62 & 9.5 & $15.9(3.04)$ \\
\hline & 50 & 63 & 25.3 & $15.9(3.92)$ \\
\hline & 100 & 62 & 86.9 & $13.2(2.63)$ \\
\hline & 125 & 48 & 95.5 & $13.7(2.24)$ \\
\hline & 150 & 54 & 100 & $12.9(2.28)$ \\
\hline \multirow[t]{6}{*}{ permethrin } & 0 & 60 & 13.2 & $15.1(3.15)$ \\
\hline & 10 & 60 & 45.0 & $13.0(3.45)$ \\
\hline & 30 & 60 & 15.0 & $15.8(3.3)$ \\
\hline & 50 & 59 & 53.7 & $14.7(3.37)$ \\
\hline & 70 & 60 & 82.5 & $13.7(3.39)$ \\
\hline & 90 & 60 & 82.5 & $12.9(2.39)$ \\
\hline \multirow[t]{6}{*}{ imidacloprid } & 0 & 70 & 10 & $15.0(2.12)$ \\
\hline & 0.5 & 69 & 23.2 & $12.9(2.28)$ \\
\hline & 10 & 60 & 35.0 & $12.6(2.29)$ \\
\hline & 20 & 70 & 71.4 & $12.5(1.90)$ \\
\hline & 30 & 70 & 84.3 & $12.87(1.92)$ \\
\hline & 40 & 70 & 90.0 & $12.4(1.88)$ \\
\hline
\end{tabular}




\section{Table 2 (on next page)}

Topical toxicity of dimethoate, permethrin, and imidacloprid to Megachile rotundata females.

The toxicity of each insecticide was determined with statistical models that included or did not include the body mass of individual bees as a covariate. Wald test $X^{2}$ statistics are provided for both the effect of treatment and the effect of mass, where a large test statistic and significant $P$ value indicate a significant effect on the model. Model parameters were generated using probit-transformed mortality data and untransformed dose data. 


\begin{tabular}{|c|c|c|c|c|c|c|c|c|}
\hline Insecticide & $\begin{array}{c}\text { Individual mass } \\
\text { included as covariate }\end{array}$ & $\begin{array}{c}\mathrm{LD}_{50}( \pm 95 \% \mathrm{CI}) \\
(\text { ng a.i./bee })\end{array}$ & $\begin{array}{l}\text { Slope at } \\
\text { the } L D_{50}\end{array}$ & $\begin{array}{c}\text { Wald } X^{2} \\
\text { treatment }\end{array}$ & $\begin{array}{l}\text { Wald } X^{2} P \\
\text { treatment }\end{array}$ & $\begin{array}{c}\text { Wald } X^{2} \\
\text { mass }\end{array}$ & $\begin{array}{c}\text { Wald } X^{2} P \\
\text { mass }\end{array}$ & $\overline{\text { Pseudo } \mathrm{R}^{2}}$ \\
\hline \multirow[t]{2}{*}{ dimethoate } & No & $69.84(7.97)$ & $2.62 \mathrm{e}^{-2}$ & 256.03 & $<0.0001$ & NA & NA & 53.57 \\
\hline & Yes & $61.74(8.56)$ & $2.85 \mathrm{e}^{-2}$ & 256.03 & $<0.0001$ & 98.14 & $<0.0001$ & 74.11 \\
\hline \multirow[t]{2}{*}{ permethrin } & No & $53.49(8.25)$ & $2.13 \mathrm{e}^{-2}$ & 59.142 & $<0.0001$ & NA & NA & 17.88 \\
\hline & Yes & 44.89 (8.17) & $2.66 \mathrm{e}^{-2}$ & 29.142 & $<0.0001$ & 92.69 & $<0.0001$ & 45.84 \\
\hline \multirow[t]{2}{*}{ imidacloprid } & No & $17.36(2.73)$ & $6.13 \mathrm{e}^{-2}$ & 114.16 & $<0.0001$ & NA & NA & 28.75 \\
\hline & Yes & $12.90(3.05)$ & $6.38 \mathrm{e}^{-2}$ & 282.87 & $<0.0001$ & 57.50 & $<0.0001$ & 43.24 \\
\hline
\end{tabular}

1 


\section{Table 3 (on next page)}

Toxicity of dimethoate, permethrin, and imidacloprid to Megachile rotundata $72 \mathrm{~h}$ after topical exposure.

$\mathrm{LD}_{50}$ values for $M$. rotundata from this study are presented along with the relative toxicity to Apis mellifera and previous estimates for $M$. rotundata. $L_{50}$ values incorporating mean body mass for each species are estimated using the mean mass of individual $M$. rotundata adults in this study and the mean mass of individual $A$. mellifera adults. 


\begin{tabular}{lccc}
\hline Pesticide & $\begin{array}{c}\mathbf{L D}_{\mathbf{5 0}}(\mathbf{\pm 9 5 \%} \mathrm{CI}) \\
(\mathbf{n g} \text { a.i./bee })\end{array}$ & $\begin{array}{c}\text { Toxicity ratio to honey bees } \\
\text { (per bee) }\end{array}$ & $\begin{array}{c}\text { Toxicity ratio to honey bees } \\
\text { (per mean body mass) }\end{array}$ \\
\hline dimethoate & $62.08(7.05)$ & $1: 3.75^{\mathrm{a}}$ & $1: 0.4 \mathrm{~d}^{\mathrm{c}}$ \\
permethrin & $50.01(8.17)$ & $1: 1.46^{\mathrm{b}}$ & $1: 0.16^{\mathrm{b}, \mathrm{c}}$ \\
imidacloprid & $12.82(2.78)$ & $1: 6.13^{\mathrm{b}}$ & $1: 0.62^{\mathrm{b}, \mathrm{c}}$
\end{tabular}

$1 \quad$ a OECD, (1998b); ${ }^{\mathrm{b}}$ Sanchez-Bayo \& Goka, (2014); ${ }^{\mathrm{c}} E P A,(2012)$. 


\section{Table 4 (on next page)}

Hazard quotients of imidacloprid, dimethoate, and permethrin to Megachile rotundata.

Hazard quotients were calculated using acute topical toxicity values and the highest legal application rate from a formulated product containing each insecticide that is currently registered in Canada and the United States. The trigger value for solitary bees suggested by (EFSA, 2013) is a hazard quotient of 8-16 g a.i./ha/ $\mu \mathrm{g}$ a.i./bee . 


\begin{tabular}{|c|c|c|c|}
\hline Insecticide & $\begin{array}{c}\mathrm{LD}_{50}( \pm 95 \% \mathrm{CI}) \\
(\mathrm{ng} \text { a.i./bee })\end{array}$ & $\begin{array}{c}\text { Highest application } \\
\text { rate (g a.i./ha) }\end{array}$ & $\begin{array}{c}\text { Hazard quotient } \\
\left(\frac{\text { g a.i. } / \mathbf{h a}}{\mu \mathrm{g} \text { a.i./bee }}\right)\end{array}$ \\
\hline dimethoate & $62.08(7.05)$ & $1104^{\mathrm{a}}$ & 17783.51 \\
\hline permethrin & $50.01(8.17)$ & $70^{\mathrm{b}}$ & 1399.72 \\
\hline imidacloprid & $12.82(2.78)$ & $48^{c}$ & 3744.15 \\
\hline
\end{tabular}

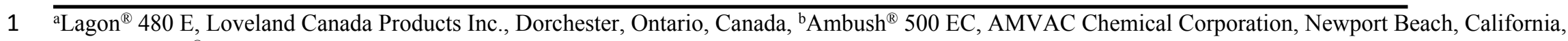

2 USA, ${ }^{\circ}$ Admire ${ }^{\circledR}$ 240, Bayer CropScience Inc., Calgary, Alberta, Canada. 